\title{
TANTANGAN DAN PELUANG PEMBELAJARAN BAHASA DAN SASTRA INDONESIA DI ERA REVOLUSI INDUSTRI 4.0
}

\author{
Syanurdin \\ Guru Besar FKIP-UNIHAZ Bengkulu \\ Syanurdin Ma'ruf@gimail.com
}

\begin{abstract}
Abstrak
Perkembangan ilmu pengetahuan dan teknologi pada awal abad 20 telah melahirkan teknologi informasi yang dikendalikan secara ototmatis. Teknologi informasi tersebut menjadi dasar dalam kehidupan manusia, dimana penggunaan komputer tidah terbatas sebagai akibat dari perkembangan internet dan digital di era revolusi 4.0. Hal itu mengakibatkan segala hal menjadi tanpa batas. Era ini dipercaya akan mengalami perubahan yang fundamental, tanpa kecuali dalam pembelajaran bahasa dan sastra Indonesia. Akibatnya, banyak tantangan dan sekaligus peluang muncul dalam pembelajaran. Pembelajaran harus merujuk pada 4 karakter belalar abad 21, yaitu: berpikir kritis dan pemecahan masalah, kreatif dan inovasi, kolaborasi, dan komunikasi. Untuk itu dibutuhkan sosok guru yang terbuka, adaptik, dan akomodatif sekaligus mampu menciptakan atmosfir belajar yang menantang.
\end{abstract}

Kata kunci: Tantangan dan peluang pembelajaran bahasa

\begin{abstract}
The development of science and technology in the early 20th century has given birth to information technology that is controlled automatically. Information technology has become the basis in human life, where the use of computers is not limited as a result of the development of the internet and digital in the 4.0 revolution era. That results in everything becoming limitless. This era is believed to undergo fundamental changes, without exception in learning Indonesian language and literature. As a result, many challenges and opportunities arise at the same time in learning. Learning must refer to four 21st century character traits, namely: critical thinking and problem solving, creative and innovation, collaboration, and communication. For this reason, teachers are required to be open, adaptive, and accommodating while at the same time able to create a challenging learning atmosphere.
\end{abstract}

Keywords: Challenges and opportunities for language learning

\section{PENDAHULUAN}

Perkembangan ilmu pengetahuan dan teknologi pada awal abad 20 telah melahirkan teknologi informasi dan proses produksi yang dikendalikan secara ototmatis. Mesin industri telah menggunakan sistem otomatisasi berbasis komputer yang selama ini dikendalikan oleh tenaga manusia. Dampaknya, biaya produksi menjadi semakin murah seiring dengan pesatnya teknologi informasi yang terus bergerak maju. Kemajuan teknologi yang mengintegrasikan dunia fisik, digital, dan biologis tersebut telah mempengaruhi semua disiflin ilmu.

Revolusi industri 4.0 merupakan revolusi industri yang dapat dikatakan berbeda dengan revolusi industri sebelumnya. Revolusi industri generasi ke-4 ini memiliki skala, ruang lingkup, dan kompleksitas yang lebih luas, sehingga mendorong otomatisasi dalam semua proses aktivitas kehidupan. Teknologi internet yang semakin canggih dapat menghubungkan jutaan manusia di seluruh dunia yang sekaligus menjadi basis transaksi perdagangan dan transfortasi online. Demikian pula, aplikasi media sosial, bioteknologi dan nonteknologi semakin menegaskan bahwa dunia dan kehidupan manusia telah berubah secara fundamental (Suwandi, 2018). 
Tidak dapat dipungkiri bahwa revolusi industri 4.0 tersebut membuka peluang yang luas bagi siapapun yang ingin maju. Arus informasi yang melimpah menyediakan manfaat besar untuk pengembangan ilmu pengetahuan, ilmu ekonomi, termasuk dalam mengembangkan dunia pendidikan. Lebih khusus lagi bagi pengembangan pembebelajaran bahasa dan sastra Indonesia. Dimana daya jangkau teknologi informasi tersebut tidak hanya berskala lokal, tetapi sampai skala global. Peluang itu memiliki akses tinggi untuk terlibat aktif memberikan dan membagikan opini kepada masyarakat melalui media sosial online.

Namun perlu disadari bahwa kemajuan teknologi informasi tersebut tidak hanya membawa pengetahuan positif saja, tetap juga ada negatif. Kemampuan seseorang untuk mengolah pengetahuan (knowledge) menjadi suatu kearifan (wisdom) dalam lingkungan sosial akan menentukan tingkat ketahanan di era revolusi itu. Nilai-nilai tidak etis yang dapat menciptakan kegaduhan publik perlu disaring dengan bijak, termasuk dalam menyaring informasi hoaks (Suwandi, 2018).

Di samping ada peluang di atas juga ada tantangan dalam revolusi industri tersebut, khususnya dalam beradaptasi dengan perubahan itu. Seseorang pekerja harus memiliki kemampuan yang tidak akan bisa dilakukan oleh mesin, yaitu kemampuan untuk memecahkan masalah (kreativitas). Para pekerja harus memiliki soft skill untuk memecahkan masalah yang kompleks, berpikir kritis, kreativitas, manajemen manusia, berkoordinasi dengan orang lain, kecerdasan emosional, penilaian dan pengambilan keputusan, beroreintasi servis, negosiasi, dan fleksibilitas kognitif. Soft skill itu menjadi salah satu dari faktor penting untuk dimiliki para pekerja di masa depan. Pada umumnya, industri menekankan kebutuhan akan karyawan yang bisa terus belajar, cepat beradaptasi, dan melek teknologi.

\section{A. TANTANGAN PEMBELAJARAN BAHASA}

Dalam sistem pendidikan pun perlu menekankan pengembangan soft skill. Generasi milenial ke depan harus mampu beradaptasi secara cepat terhadap perubahan dan memiliki bekal mumpuni untuk menghadapi masa depan di tengah geliat revolusi 4.0. Di bawah ini akan ditampilkan hasil analisis yang berkaitan dengan masalah pembelajaran bahasa. Ada tiga macam tantangan yang harus dihadapi oleh guru bahasa dan sastra Indonesia dalam proses pembelajaran yaitu:

\section{Membangun Atmosfir Pembelajaran yang Menantang}

Sebagaimna telah disebutkan di atas bahwa revolusi industri generasi ke-4 ini memiliki skala, ruang lingkup, dan kompleksitas yang lebih luas, sehingga mendorong otomatisasi dalam semua proses aktivitas kehidupan. Teknologi internet yang semakin canggih dapat menghubungkan jutaan manusia di seluruh dunia yang sekaligus menjadi basis transaksi perdagangan dan transfortasi online. 
Aplikasi media sosial, bioteknologi dan nonteknologi semakin menegaskan bahwa dunia dan kehidupan manusia telah berubah secara fundamental. Untuk menghadapi era tersebut tugas guru tidak ringan, tanggung jawab tersebut sepatutnya dipandang guru sebagai tantangan yang harus ditunaikan. Oleh karena itu, guru perlu memiliki pengetahuan teknologi (technological knowledge), yakni pengetahuan tentang bagaimana menggunakan hardware dan software sekaligus menghubungkan antara keduanya. Guru dituntut pula perlu memiliki kompetensi isi materi pelajaran (content knowledge), kompetensi paedagogik (pedagogical knowledge) yang meliputi: pengetahuan tentang karaktristik siswa, teori belajar, metode pembelajaran, penilaian pembelajaran, dan hasil belajar siswa. Di samping itu pula, guru perlu memiliki kemampuan teknis, kreativitas, dan pemecahan masalah yang inovatif (Suwandi, 2018).

Aspek lain yang semakin menarik manakalah guru menyadari bahwa siswa abad XXI datang ke sekolah dengan pengalaman dan harapan yang berbeda dengan siswa di abad XX, tatkala guru dahulu masih menjadi siswa. Penggunaan digital yang pintar, multi-media, multi tasking kehidupan sehari-hari yang sangat berbeda dengan siswa beberapa dekade yang lalu. Siswa itu pun belajar dengan gaya dan cara yang berbeda. Oleh karena itu, penumbuhkembangkan minat dan motivasi belajar bagi mereka pun berbeda, maka pendekatan dan pola interaksi yang dipraktikkan guru pun berbeda. Siswa lebih membutuhkan guru yang terbuka, adaptif, dan akomodatif terhadap berbagai kebutuhan siswa, baik untuk penyediaan materi ajar, penggunaan model pembelajaran, teknik penilaian, dan penciptaan atmospir belajar yang menantang.

\section{Mengembangkan Kurikulum dengan Scientific Approach}

Pada abad XXI perlu mengacu pada 3 konsep pendidikan, yaitu: keterampilan abad 21 (21st century skill), pendekatan saintifik (scientific approach), dan penilaian autentik (authentic assesment). Implikasinya bagi guru bahwa pembelajaran harus merujuk pada 4 karakter belajar abad 21 kata Trimansyah, (2019) yaitu berpikir kritis dan pemecahan masalah, kreatif dan inovasi, kolaborasi, dan komunikasi atau dikenal dengan 4C (critical thinking and problem solving, creative and inovation, collaboration, dan communication).

Pola pikir dan prilaku guru hendaknya sesuai dengan yang dikembangkan dalam kurikulum K-13. Dimana tuntutan pembelajaran berpusat pada siswa merupakan suatu keniscayaan. Siswa harus memiliki pilihan-pilihan terhadap materi pelajaran untuk memiliki kompetensi yang sama. Pembelajaran bersifat interaktif, yakni terjadi interaksi guru—siswa-masyarakat-lingkungan alam, sumber/media lainnya. Pembelajaran terisolasi harus diubah menjadi pembelajaran secara jejaring (siswa dapat menimba ilmu dari siapa saja dan dari mana saja yang dapat dihubungi serta diperoleh melalui internet). Pembelajaran aktif-mencari perlu secara terus-menerus diperkuat melalui penerapan pendekatan saintifik. Pembelajaran dengan alat tunggal harus digesier menjadi 
berbasis multimedia. Pembelajaran harus berbasis pada kebutuhan pelanggan (users) dengan memperkuat pengembangan potensi khusus yang dimiliki setiap siswa. Ditegaskan Arend (2008) di era revolusi 4.0 bahwa sekolah kemungkinan besar akan terus berbasis-masyarakat, dan guru akan terus melaksanakan tugas pembelajaran kepada kelompok-kelompok anak di ruang-ruang kelas.

Tantangan yang dihadapi guru pada era komputer dan teknologi digital makin kompleks. Arend (2008) mengajukan pandangan bahwa tantangan mengajar guru abad 21 meliputi: (1) mengajar dalam masyarakat multikultural, (2) mengajar untuk mengonstruk makna, (3) mengajar untuk mempelajarkan aktif, (4) mengajar dan akuntabilitas, (5) mengajar dan pilihan, (6) mengajar dengan pandangan baru tentang kemampuan, dan (7) mengajar dan teknologi.

Mengajar siswa dengan latar belakang bahasa dan budaya yang beragam dan dengan kebutuhan khusus menuntut guru untuk memiliki strategi dan metode efektif yang jauh melampawi apa yang sebelumnya dituntut dari guru. Guru harus mempu mendeferensiasi kurikulum dan pengajarannya agar lebih sesuai dengan relevansi kehidupan siswa.

\section{Menuntun Siswa Belajar Sepanjang Hayat}

Siswa akan terus belajar secara aktif apabila kondisi pembelajaran dibuat menyenangkan, nyaman, dan jauh dari prilaku yang menyakitkan perasaan siswa. Sangat diperlukan suasana belajar yang menyenangkan karena otak tidak akan bekerja optimal bila perasaan dalam keadaan tertekan. Di sini kata Brown (2000) guru memiliki tugas penting membimbing dan memfasilitasi siswa dalam belajar. Demikian pula Suwandi (2013) mengatakan tanggung jawab untuk menciptakan situasi yang mendorong prakarsa, motivasi, dan tanggung jawab siswa untuk belajar sepanjang hayat.

\section{B. PELUANG PEMBELAJARAN BAHASA}

Guru memiliki peran sangat strategis karena keberadaannya sangat menentukan keberhasilan pembelajaran. Guru harus merupakan pribadi yang harus mampu menerjemahkan dan menjabarkan nilai-nilai yang terdapat dalam kurikulum, sekaligus mentransformasikan nilai-nilai tersebut kepada siswa melalui pembelajaran. Dengan harapan siswa akan dapat mencapai tujuan sebagaimana yang digariskan dalam kurikulum, sekaligus mampu memenuhi kebutuhan pengembangan dirinya.

Di bawah ini akan diuraikan secara berturut-turut peluang pembelajaran bahasa dan sastra Indonesia, setelah menganalisis tantangan-tantangan pembelajaran bahasa di era revolusi industri 4.0, yaitu: 


\section{Perlu Mengembangkan Bahan Ajar Berbasis Digital}

Di era digital menuntut guru untuk bermetamorfosis dari guru biasa menjadi guru yang luar biasa. Guru yang bukan saja melek teknologi, memiliki pengetahuan luas dan kecakapan/keterampilan tinggi di bidang yang diajarkannya, memiliki kemampuan memilih dan menggunakan metode atau strategi pembelajaran, sekaligus memerankan diri sebagai model untuk menginspirasi siswa (Suwandi, 2013).

Guru hendaknya berupaya secara terus-menerus meningkatkan kemampuannya untuk menjadi guru yang hebat yang mampu menginspirasi siswa agar mereka terlibat secara aktif, koperatif, dan bertanggung jawab dalam pembelajaran. Harmin dan Toth (2012) menyarankan ada lima potensi siswa yang dapat diarahkan guru, yaitu: dignity (martabat), energy (energi), self management (manajemen diri), community (komunitas), dan awareness (kepedulian) yang disingkat DESCA. Semua siswa dilahirkan dengan kemampuan untuk hidup dengan martabat, untuk melakukan semua tugasnya dengan berenergi, melakukan menajemen diri dengan semestinya, bekerja dengan komunitas orang lain, dan untuk peduli dengan segala hal yang terjadi di sekitar mereka.

\section{Perlu Mengembangkan Bahan Ajar Berwawasan Pendidikan Multikultural}

Bangsa Indonesia adalah negara multikultural dan masyarakat Indonesia merupakan masyarakat multikultural harus memiliki guru bahasa Indonesia. Hal tersebut sangat perlu disadari oleh para guru. Kesadaran itu akan mendorong guru mendesain pembelajaran bahasa dan sastra Indonesia bermuatan multikultural. Pendidikan itu sangat berperan penting untuk menghasilkan generasi multikultur, yakni generasi yang menghargai perbedaan, menegakkan nilai-nilai demokrasi, keadilan, dan kemanusiaan (Suwandi, 2013).

Pembelajaran bahasa dan sastra Indonesia dalam suasana multikultural menuntut guru memiliki pemahaman lintas budaya. Guru perlu memiliki wawasan yang cukup tentang bagaimana seharusnya menghargai keragaman bahasa agar segala sikap dan tingka laku menunjukkan sikap egaliter dan selalu menghargai perbedaan bahasa yang ada. Dengan wawasan tentang keberagaman bahasa guru akan memiliki kepekaan yang tinggi terhadap masalah-masalah yang menyangkut adanya diskriminasi bahasa, baik terjadi dalam kelas maupun di luar kelas.

\section{Perlu Mengembangkan Bahan Ajar Bermuatan Kecerdasan Ekologis}

Salah satu dari faktor penting dalam kurikulum 13 berkaitan dengan tantangan eksternal, antara lain yang terkait dengan arus globalisasi, terkait dengan isu masalah lingkungan hidup, kemajuan teknologi dan informasi, kebangkitan industri kreatif dan budaya, dan perkembangan pendidikan di tingkat internasional (Permendikbud No.68 Tahun 2013). Untuk itu, guru harus 
memperhatikan dan mengakomodasi berbagai tuntutan, berbagai kebutuhan siswa, baik pada skala lokal, nasional, maupun global.

Apabila mengacu pada kerangka dasar kurikulum 2013 tersebut, upaya pelestarian lingkungan selayaknya menjadi perhatian semua elemen pendidikan. Pelestarian lingkungan tidak hanya menjadi tanggung jawab guru mata pelajaran IPA atau sains, tetapi termasuk semua guru mata pelajaran, juga tidak ikut ketinggalan guru bahasa Indonesia (Syanurdin, 2017).

Penanaman sikap dan prilaku merawat lingkunang perlu diintegrasikan dalam pembelajaran bahasa Indonesia. Buku—sebagai faktor penting dalam pembelajaran dapat menjadi wahana memberikan pengetahuan, keterampilan, dan sikap positif kepada anak tentang pentingnya menjaga dan melestarikan lingkungan (ekosistem).

\section{SIMPULAN}

Sebagai akhir dari pembahasan makalah ini, maka di sini diambil beberapa kesimpulan sebagai berikut:

Revolusi industri 4.0 merupakan revolusi industri yang berbeda dengan revolusi industri sebelumnya. Revolusi industri generasi ke-4 ini memiliki skala, ruang lingkup, dan kompleksitas yang lebih luas, sehingga mendorong otomatisasi dalam semua proses aktivitas kehidupan manusia. Teknologi internet yang semakin canggih dapat menghubungkan jutaan manusia di seluruh dunia yang sekaligus menjadi basis transaksi perdagangan dan transfortasi online. Demikian pula, aplikasi media sosial, bioteknologi dan nonteknologi semakin menegaskan bahwa dunia dan kehidupan manusia telah berubah secara fundamental, tidak ketinggalan dalam pembelajaran bahasa dan sastra Indonesia.

Adapun tantangan dan peluang pembelajaran bahasa dan sastra Indonesia di era revolusi industri 4.0. yaitu: (1) Membangun atmosfir pembelajaran yang menantang, (2) Mengembangkan kurikulum dengan Scientific Approach, dan (3) menuntun siswa belajar sepanjang hayat. Sedangkan peluang pembelajaran bahasa, yaitu: (1) Perlu mengembangkan bahan ajar berbasis digital, (2) Perlu mengembangkan bahan ajar berwawasan pendidikan multikultural, dan (3) Perlu mengembangkan bahan ajar bermuatan kecerdasan ekologis.

\section{DAFTAR PUSTAKA}

Arend, R. I. (2008). Learning To Teach, Belajar untuk Mengajar (Helly Prajitno Soetjipto dan Sri Mulyantini Seotjipto, penerjemah). Yogyakarta: Pustaka Pelajar.

Brown, H.D. (2000). Principle of Language Learning and Teaching, Fouth Edition. Englewood Cliffs, NJ: Prentice Hall Regent. 
Harmin, M dan Toth, M. (2012). Pembelajaran Aktif yang Menginspirasi, Buku Pegangan Lengkap untuk Guru Masa Kini, (Bethari Anissa Ismayasari, penerjemah). Jakarta: Indeks.

Peraturan Menteri Pendidikan dan Kebudayaan Nomor 68 Tahun 2013 tentang Kerangka Dasar dan Struktur Kurikulum Sekolah Menengah Pertama/Madrasah Tsanawiyah.

Suwandi, S. (2013). Peran Guru Bahasa Indonesia yang Inspiratif untuk Mewujudkan Perserta didik Berkarakter. Dalam Saddhono, K. Et.al (ed.) Proceeding Seminar Internasional PIBSI XXXV (hlm. 1-10). Surakarta: Prodi Pendidikan Bahasa dan Sastra Indonesia FKIPUNS.

(2018). Peran Guru dalam Mengimplementasikan Pembelajaran Bahasa Indonesia. Makalah dipresentasekan pada Seminar Nasional Bahasa, Sastra, dan Pengajarannya. Diselenggarakan Fakultas Bahasa dan Seni Universitas Pendidikan Ganesha, Singaraja, Bali.

Syanurdin. (2017). Model Materi Ajar Menulis Bahasa Indonesia (Mata Kuliah Wajib Umum MKWU Bahasa Indonesia di Perguruan Tinggi. Bengkulu: Penerbit Vanda.

Trimansyah, Bambang. (2019). Modul Literasi Menulis. Jakarta: Pusat Pembinaan Bahasa dan Sastra Badan Pengembangan Bahasa dan Perbukuan Kementerian Pendidikan dan Kebudayaan RI. 